\title{
ELEMENTOS TECNOLÓGICOS DETERMINANTES DAS CAPACIDADES DINÂMICAS DE INOVAÇÃO E COOPERAÇÃO: UM ESTUDO COM AS MULTINACIONAIS BRASILEIRAS
}

\section{RESUMO}

O objetivo geral foi avaliar os elementos tecnológicos que determinam os resultados da cooperabilidade nas Multinacionais Brasileiras (MNB). Quanto à metodologia de pesquisa, realizou-se um levantamento junto ao universo de MNB, sendo que uma amostra definitiva de 60 empresas responderam um questionário estruturado. A análise dos dados quantitativos foi processada pelo software SPSS (Statistical Package for Social Sciences) versão 17.0., cujos testes estatísticos realizados foram o Alpha de Cronbach, a análise fatorial, a Correlação, o Componente Principal e a Regressão Múltipla. Os resultados do estudo evidenciaram o perfil das MNB e possibilitaram a avaliação dos elementos da trajetória tecnológica e dos insumos tecnológicos que interferem nos resultados da cooperabilidade.

Palavras-chave: Elementos Tecnológicos; Capacidades Dinâmicas; Multinacionais Brasileiras.

\section{TECHNOLOGICAL FACTORS DETERMINING THE DYNAMICS OF INNOVATION AND SKILLS DEVELOPMENT: A STUDY WITH BRAZILIAN MULTINATIONAL}

\begin{abstract}
The overall objective was to evaluate the technological elements that determine the results of the Brazilian Multinationals cooperability (MNB). Regarding research methodology, we carried out a survey among the universe of MNB, with a final sample of 60 companies answered a structured questionnaire. The quantitative data analysis was conducted using the software SPSS (Statistical Package for Social Sciences) version 17.0., Statistical tests were performed Cronbach's alpha, factor analysis, Correlation, the Principal Component and Multiple Regression. The results of the study showed the profile of the MNB and enabled the evaluation of the elements of the technological trajectory and technological inputs that affect the results of cooperability.
\end{abstract}

Keywords: Technological Elements; Dynamic Capabilities; Brazilian Multinationals. 


\section{FACTORES TECNOLÓGICOS QUE DETERMINAN LA DINÁMICA DE LA INNOVACIÓN Y \\ DESARROLLO DE HABILIDADES: UN ESTUDIO CON BRASILEÑO MULTINACIONAL}

\section{RESUMEN}

El objetivo general fue evaluar los elementos tecnológicos que determinan los resultados de las multinacionales brasileñas cooperabilidade (MNB). En cuanto a la metodología de la investigación, se realizó una encuesta en el universo de la Brigada Multinacional, con una muestra final de 60 empresas respondieron a un cuestionario estructurado. El análisis de los datos cuantitativos se procesó por (Statistical Package for Social Sciences) versión 17.0., El software estadístico SPSS cuyas pruebas eran el alfa de Cronbach, análisis factorial, correlación, componentes principales y regresión múltiple. Los resultados del estudio mostraron que el perfil del MNB y permitieron a la evaluación de los elementos de la trayectoria tecnológica e insumos tecnológicos que influyen en los resultados de cooperabilidade.

Palabras clave: elementos tecnológicos; Capacidades dinámicas; Multinacionales brasileñas.

Priscila Rezende da $\operatorname{Costa}^{1}$ Geciane Silveira Porto ${ }^{2}$

\footnotetext{
${ }^{1}$ Doutora em Administração pela Faculdade de Economia, Administração e Contabilidade da Universidade de São Paulo - FEA/USP. ACoordenadora da Universidade Nove de Julho - UNINOVE. Brasil. E-mail: priscilarc@uninove.br

${ }^{2}$ Doutora em Administração pela Universidade de São Paulo - USP. Professora da Universidade de São Paulo - USP. Brasil. E-mail: geciane@usp.br
} 


\section{INTRODUÇÃO}

Os mercados se tornam cada vez mais dinâmicos na atualidade, e, novas formas de competição surgem fazendo com que as companhias busquem se adaptar e explorar as mudanças em seus ambientes de negócios procurando oportunidades para criar novos ciclos tecnológicos e estratégicos (Teece, 2007). Conviver e explorar mudanças é um empreendimento inerente à atividade empresarial, no entanto, para sobreviver e prosperar sob condições de mudança, as empresas devem desenvolver "capacidades dinâmicas" para criar, ampliar e modificar as formas pelas quais sobrevivem (Helfat et al., 2007).

Para desenvolver "capacidades dinâmicas", principalmente as relacionadas à inovação, faz-se necessário compreender a sua dispersão (Andrade, 2010). Isso implica que uma empresa, sozinha, não tem todas as capacidades de que precisa; ao contrário, elas estão cada vez mais espalhadas em contextos internos e externos. Essas capacidades, por sua vez, não são desenvolvidas de maneira isolada, dependendo muitas vezes de processos inovadores interativos ou de simples troca (Chesbrough, Vanhaverbeke \& West, 2008).

A capacidade dinâmica de inovar e a gestão dos seus atributos de dispersão e interação são, portanto, fatores essenciais à sobrevivência e ao êxito de uma empresa no século 21 e se, no passado, era uma necessidade apenas de um grupo seleto de grandes empresas já estabelecidas, advindas de países desenvolvidos, hoje é também uma prioridade para muitas empresas emergentes originadas dos países em desenvolvimento (Hitt, 2008). Cabe destacar que no contexto de crescimento e de competitividade das empresas emergentes o desafio atual não depende unicamente da geração local de inovações de produtos e processos, mas envolve a capacidade dinâmica de gerar soluções inovadoras e novos modelos de negócio também em escala global, emergindo, então, o desafio competitivo da internacionalização (Doz, Santos \& Williamson, 2001).

Santos (2006) ressalta que o sucesso futuro das multinacionais emergentes, especificamente as brasileiras, dependerá, cada vez mais, da capacidade de acessar o conhecimento fora das subsidiárias e da matriz e de juntá-lo às capacidades de suas redes globais de operações e de cooperação tecnológica (Almeida et al., 2007). Esta construção exigirá intensa melhora da capacidade de organizar o conhecimento que se encontra disperso em sua vasta rede de subsidiárias e parceiros tecnológicos (Cyrino \& Barcellos, 2006).

Ao mobilizar e compartilhar conhecimentos dispersos globalmente, as multinacionais emergentes poderão então inovar de forma mais eficaz e com resultados superiores aos dos seus rivais que continuam presos à própria nacionalidade (Leydesdorff \& Etzkowitz, 2001). É, exatamente nesse ponto, onde o valor de uma empresa é determinado pela criação, ampliação e modificação das formas pelas quais ela se mantém inovadora e competitiva no mercado local e global, que a cooperação com fontes externas assume um papel de destaque, pois com a cooperação tem-se a possibilidade de integrar os atores ofertantes e demandantes de inovação e estes podem gerar dinamicamente caminhos para compartilhar competências e gerar conhecimentos e inovações muitas vezes difíceis e/ou inviáveis de serem gerados individualmente (Leydesdorff \& Meyer, 2006).

Apesar dos benefícios potenciais, as atividades de cooperação requerem esforço e dedicação das partes envolvidas (SIMARD; WEST, 2008), além de procedimentos estratégicos, gerenciais e estruturais que devem ser desenvolvidos e comumente aceitos, implementados e flexibilizados pelos parceiros, resultando, portanto, no desenvolvimento de aptidões e competências não só tecnológicas, mas de gestão dos recursos tangíveis e intangíveis (Carayannis \& Campbell, 2009).

Em virtude destes desafios, há um interesse acadêmico e empresarial cada vez maior no que tange às características das organizações que criaram uma capacidade de cooperação diferenciada, incluindo as relações mais complexas e desafiadoras, pois elas resultam na expansão da base de recursos dos parceiros e na criação de valores específicos que emergem dos ativos e recursos envolvidos nas relações cooperativas (Hanel \& Pierre, 2006). As empresas que são capazes de, sistematicamente, conseguir ganhos com a cooperação normalmente adotam técnicas formais de gestão para conduzi-la, utilizam um processo gerencial proposital e estruturam as decisões de cooperação (Berghe \& Guild, 2008).

Considerando as reflexões até aqui apresentadas, faz-se necessário articular o conceito da cooperabilidade no contexto das multinacionais emergentes, cuja definição pode ser assim sumarizada: Cooperabilidade é a capacidade intencional de desenvolver dinamicamente projetos cooperativos, onde os parceiros criam elou compartilhar recursos tecnológicos e inovadores em contextos locais elou globais.

Adotando-se o conceito da cooperabilidade, os desafios das multinacionais emergentes serão mais complexos, pois essas empresas deverão desenvolver e sistematizar estratégias, estruturas e práticas administrativas para a busca, seleção, implementação e gerenciamento das relações cooperativas locais e globais. Além disso, o conceito de cooperabilidade prevê que as relações de cooperação, particularmente 
as focadas em inovação e tecnologia, podem ser desenvolvidas com os mais diversos parceiros externos, o que exigirá dessas multinacionais o desenvolvimento de habilidades organizacionais para lidar e gerenciar o relacionamento com diferentes fontes de inovação.

Diante desta problemática, objetiva-se avaliar os elementos tecnológicos que determinam os resultados da cooperabilidade nas Multinacionais Brasileiras (MNB). Especificamente, procura-se: (a) analisar o perfil das MNB, (b) avaliar se os elementos da trajetória tecnológica interferem nos resultados da cooperabilidade e (c) avaliar se os insumos tecnológicos afetam os resultados da cooperabilidade. Vale destacar que o objeto de estudo da pesquisa está relacionado às multinacionais brasileiras (matriz como lócus de investigação), aqui definidas como empresas (1) de capital nacional (maior ou igual a 50\% do capital controlador), (2) com unidades produtivas ou comerciais no exterior, (3) que mantenham unidades de P\&D internacionais ou possuam projetos cooperativos com ICT (Instituições Científicas e Tecnológicas) estrangeiras.

\section{REFERENCIAL TEÓRICO}

\subsection{Cooperabilidade: Trajetória e Insumos Tecnológicos}

Mesmo sendo um tema de fronteira, foi possível identificar na literatura os determinantes potenciais da cooperabilidade, sintetizados neste trabalho em "elementos da trajetória tecnológica" e "insumos tecnológicos". Os elementos da trajetória abordam a intensidade da experiência em P\&D e em cooperação e o grau de importância das estratégias de capacitação para a inovação que foram adotadas ao longo do seu histórico empresarial. Já os insumos tecnológicos estão associados aos propulsores empresariais da inovação aberta no médio e longo prazo, incluindo o investimento em $\mathrm{P} \& \mathrm{D}$, o faturamento dos novos produtos e a amplitude do portfólio de projetos de inovação (internos, de cooperação nacional e de cooperação internacional). A seguir são apresentadas as discussões teóricas que fundamentaram as hipóteses de pesquisa, considerando, portanto, os elementos da trajetória e insumos tecnológicos que podem afetar a capacidade dinâmica de inovação e cooperação.

Veugelers e Cassiman (2005) demonstraram que a trajetória de $\mathrm{P} \& \mathrm{D}$ afeta positivamente a probabilidade de estabelecer colaborações com universidades. Bercovitz e Feldman (2006) concluíram que o desenvolvimento contínuo de atividades de pesquisa ao longo do histórico empresarial está positivamente relacionado ao estabelecimento de relações com universidades. Também Laursen e Salter (2004) e Petruzzelli (2011), sugeriram que as empresas que acumulam experiência em inovação aberta são mais propensas a colaborar com as universidades. Dessa forma, verifica-se que a experiência interna em $P \& D$ pode afetar os resultados da cooperabilidade, sendo oportuna a apresentação das seguintes hipóteses nulas: ( $\left.H_{01}\right)$ A experiência acumulada em $P \& D$ na Matriz não determina os resultados da cooperabilidade; $\left(\mathrm{H}_{02}\right) \mathrm{A}$ experiência acumulada em $P \& D$ nas subsidiárias estrangeiras não determina os resultados da cooperabilidade.

Autores como Sampson (2005), Hoang e Rothaermel (2005 e 2010) e Lai et al. (2010) também verificaram que um dos determinantes mais importantes do desempenho das parcerias focadas em inovação é a experiência em cooperar. Aprendendo com as parcerias antigas, uma empresa refina seus mecanismos de cooperação, modifica suas interações, e reconfigura a alocação de recursos para atingir, subsequentemente, melhores desempenhos nas parcerias futuras (Lavie \& Rosenkopf, 2006). Dessa forma, ao institucionalizar várias experiências em rotinas de cooperação e ampliar sua base de conhecimento no que diz respeito à execução da cooperação, uma empresa poderá então antecipar e responder às contingências das parcerias (Kim \& Song, 2007; Bruneel et al., 2010). Diante desse contexto, verifica-se que a experiência em cooperação pode afetar os resultados da cooperabilidade, sendo oportuna a apresentação das seguintes hipóteses nulas: $\left(H_{03}\right)$ A experiência acumulada em cooperação nacional não determina os resultados da cooperabilidade; $\left(H_{04}\right)$ A experiência acumulada em cooperação internacional não determina os resultados da cooperabilidade.

De forma complementar, Chiaroni et al. (2011) e Ferro (2010), revelaram que as empresas inovadoras bem-sucedidas adotaram, ao longo da trajetória empresarial, estratégias de capacitação de curto, médio e longo prazos, tais como: a mudança na estrutura organizacional, com a criação de unidades organizacionais independentes dedicadas à gestão da P\&D interna e dos projetos de inovação aberta (West \& Gallagher, 2008); a formação de redes internas capazes de acessar e integrar os conhecimentos adquiridos externamente (O'Connor, 2008); a criação de redes interorganizacionais (ou externas), que devem agir como capacitadoras da empresa no que tange aos fluxos de entrada e saída de conhecimentos, inovações e ideias (O’Connor, 2008); o desenvolvimento de um projeto piloto que servirá como um teste de campo para os procedimentos de inovação aberta que, mais tarde, serão sintonizados, aceitos e ampliados por toda a organização (Engeroff \& Balestrin, 2008); e, por fim, a exploração dos conhecimentos gerados dentro e fora da empresa para desenvolver e explorar a inovação, envolvendo tanto a utilização de plataformas e ferramentas de tecnologia da informação e comunicação, quanto à adoção de sistemas adequados de gestão de propriedade intelectual (Chesbrough et al., 2008). Dessa forma, 
espera-se que as estratégias de capacitação para a inovação podem afetar os resultados da cooperabilidade, o que será testado por meio da seguinte hipótese nula: (H05) O grau de relevância das estratégias de capacitação tecnológica não determina os resultados da cooperabilidade.

Por fim, autores como Asakawa (2010), Bruneel et al. (2010), Chiaroni et al. (2011) e Gassmann et al. (2010) relatam que determinados insumos tecnológicos empresariais atuam como propulsores da inovação aberta no médio e longo prazo, tais como: investimentos próprios em $\mathrm{P} \& \mathrm{D}$; prospecção de fontes externas de fomento para a inovação; manutenção e renovação do portfólio de novos produtos e os faturamentos decorrentes; amplitude do portfólio de projetos internos e cooperativos de inovação, envolvendo parceiros nacionais e internacionais. A partir dessa reflexão foram elaboradas as seguintes hipóteses nulas: ( $\left.H_{06}\right)$ O grau de investimento em $P \& D$ não determina os resultados da cooperabilidade; ( $\left.\mathrm{H}_{07}\right)$ A porcentagem do faturamento advinda dos novos produtos determina os resultados da cooperabilidade; ${ }_{\left(H_{08}\right)}$ O Número de projetos de inovação desenvolvidos internamente não determina os resultados da cooperabilidade; $\left(H_{09}\right)$ O Número de projetos de inovação desenvolvidos com parceiros nacionais não determina os resultados da cooperabilidade; $\left(H_{010}\right) O$ Número de projetos de inovação desenvolvidos com parceiros internacionais não determina os resultados da cooperabilidade; $\left(H_{011}\right)$ O Número de projetos de inovação desenvolvidos com parceiros nacionais $e$ internacionais não determina os resultados da cooperabilidade.

\section{METODOLOGIA DE PESQUISA}

A pesquisa foi qualitativa, pois buscou-se verificar as hipóteses previamente formuladas e identificar a existência ou não de relações entre variáveis (Lima, 2008). A pesquisa também assumiu uma conotação descritiva, uma vez que se buscou a descrição das características do fenômeno da cooperabilidade no contexto das MNB, conforme a classificação de Gil (2002). Já o método utilizado foi o levantamento, que segundo Kerlinger (1980), procura determinar a incidência e distribuição das características e opiniões de populações de pessoas obtendo e estudando as características e opiniões de amostras e presumivelmente representativas de tais populações.

$\mathrm{O}$ universo da pesquisa foi representado por $166 \mathrm{MNB}$ industriais, comerciais e prestadoras de serviço com unidades produtivas ou comerciais no exterior, identificadas a partir de fontes secundárias de evidências, tais como o Projeto GINEBRA, a Fundação Dom Cabral, o Valor Econômico e a SOBEET. Desse universo realizou-se uma estratificação para atender o escopo da tese e então identificar as MNB que de fato detinham unidades de P\&D internacionais ou que desenvolveram projetos cooperativos com ICT estrangeiras nos últimos três anos. Para realizar essa estratificação foram estabelecidos contatos telefônicos com os responsáveis pelas áreas de $\mathrm{P} \& \mathrm{D}$ ou Engenharia, além disso, recorreu-se aos sites institucionais das MNB e aos Relatórios Anuais da Administração das MNB de capital aberto que estão disponíveis no site da CVM. A estratificação resultou em 73 MNB que internacionalizaram as atividades internas ou cooperativas de P\&D e, desse total, 60 MNB manifestaram interesse em participar da pesquisa.

Para a amostra das $60 \mathrm{MNB}$ aplicou-se um questionário estruturado, onde se utilizou predominantemente a escala tipo Likert de sete pontos, iniciando com a pontuação 1 e terminando com 7 , que continham afirmações elaboradas de forma a obter a percepção e/ou opinião dos respondentes sobre os elementos que determinam a capacidade dinâmica de cooperar local e globalmente. O questionário foi disponibilizado na web para facilitar o acesso das empresas e também no formato Word. Em seguida, diretores ou coordenadores de P\&D ou Inovação das matrizes das MNB da amostra receberam o convite da pesquisa via $e$-mail.

A análise dos dados foi realizada por meio de técnicas estatísticas bivariadas e multivariadas, processadas pelo software SPSS (Statistical Package for Social Sciences) versão 17.0. Os testes estatísticos realizados foram o Alpha de Cronbach, a análise fatorial, a Correlação, o Componente Principal e a Regressão Múltipla (HAIR et al., 2005), cujas particularidades serão apresentadas a seguir.

A Regressão Linear, extensão da análise de correlação, tem por objetivo descrever a variação de uma variável (dependente) condicionada à variação de uma ou mais variáveis (independentes/explicativas). Os modelos de regressão com uma variável explicativa são chamados de Modelos de Regressão Linear Simples e os modelos com mais de uma variável explicativa são chamados de Modelos de Regressão Linear Múltipla (HAIR et al., 2005). Para a avaliação da qualidade do modelo de regressão e até na escolha do melhor modelo, é usada a métrica $R$-square que mede o quanto a variabilidade da variável dependente (resposta) é explicada pelo modelo, variando de 0 a 1 (quanto maior melhor). A pressuposição de que os resíduos (diferença entre os valores esperados pelo modelo e os valores observados) tenham distribuição normal com média 0 e variância $\sigma^{2}$ deve ser atendida para que o modelo seja válido, hipótese testada pelo teste de Shapiro-Wilk a um nível de significância pré estabelecido.

O modelo de regressão linear é dado por: $Y=\eta+\alpha * x 1+\beta * x+\cdots+\varepsilon_{;}$em que, $Y$ é a observação da variável dependente, ${ }^{\eta}$ é uma constante, $\alpha_{\text {o efeito da primeira variável, }} \beta$ é o efeito da segunda 
Elementos Tecnológicos Determinantes das Capacidades Dinâmicas de Inovação e Cooperação: Um Estudo com as Multinacionais Brasileiras

variável etc e o ${ }^{\varepsilon}$ é o erro aleatório associado ao modelo, com distribuição $\mathrm{N}(0, \sigma 2)$ (HAIR et al., 2005).

\section{RESULTADOS OBTIDOS}

\subsection{Perfil das MNB}

Das 60 empresas MNB que participaram desta etapa, verificou-se que $75 \%$ são empresas industriais, $23 \%$ são empresas prestadoras de serviços e apenas $4 \%$ são empresas comerciais. Além disso, constatou-se que 52,5\% empregavam acima de 500 funcionários, cuja receita operacional bruta em 2011 esteve acima de R\$ 300 milhões, indicando que as maiores empresas com maior receita também eram aquelas com maior número de funcionários em 2010 (tabela 1).

Tabela 1- Receita operacional bruta anual das MNB segundo número de funcionários.

\begin{tabular}{|c|c|c|c|c|c|}
\hline & & \multicolumn{3}{|c|}{ NÚMERO DE FUNCIONÁRIOS NO BRASIL (\%) } & Total (\%) \\
\hline & Até R\$ 90 milhões & 17,5 & 12,5 & 7,5 & $\mathbf{3 7 , 5}$ \\
\hline \multirow{2}{*}{$\begin{array}{c}\text { Receita operacional } \\
\text { bruta anual no Brasil } \\
(\%)\end{array}$} & $\begin{array}{c}\text { Entre R 90 milhões e R \$ 300 } \\
\text { milhões }\end{array}$ & 0 & 0 & 10 & $\mathbf{1 0}$ \\
\cline { 2 - 6 } & Acima de R 300 milhões & 0 & 0 & 52,5 & $\mathbf{5 2 , 5}$ \\
\hline \multicolumn{2}{|c|}{ Total (\%) } & $\mathbf{1 7 , 5}$ & $\mathbf{1 2 , 5}$ & $\mathbf{7 0}$ & $\mathbf{1 0 0}$ \\
\hline
\end{tabular}

Sobre a atução internacional das MNB estudadas, verificou-se que os casos com alta experiência produtiva no Brasil (acima de 53 anos) foram também os casos com alta experiência produtiva no exterior (Pearson qui-square $=7,345 ; \alpha=0,082$ ). Esta associação também foi observada entre experiência produtiva no exterior e o número de subsidiárias estrangeiras, assim quanto maior o número de subsidiárias, mais alta foi a experiência produtiva internacional (Pearson qui-square $=10,345 ; \alpha=0,047$ ). Esses resultados evidenciaram que há uma associação entre a experiência produtiva nacional, a experiência produtiva internacional e o número de subsidiárias estrangeiras, ou seja, as MNB mais maduras e com maior inserção internacional são também aquelas que mais acumularam experiência produtiva no contexto nacional (tabelas 2 e 3 ).

Tabela 2 - Experiência produtiva no exterior das MNB segundo a experiência produtiva no Brasil*.

\begin{tabular}{|c|c|c|c|c|c|}
\hline & & \multicolumn{3}{|c|}{ EXPERIÊNCIA PRODUTIVA NO EXTERIOR (\%) } & \multirow{2}{*}{$\begin{array}{c}\text { Total } \\
\text { (\%) }\end{array}$} \\
\hline & & $\begin{array}{c}\text { Baixa } \\
\text { (Até 5) }\end{array}$ & $\begin{array}{c}\text { Média } \\
\text { (entre 5 e 25) }\end{array}$ & $\begin{array}{c}\text { Alta } \\
\text { (Acima de 25) }\end{array}$ & \\
\hline \multirow{2}{*}{$\begin{array}{c}\text { Experiência } \\
\text { produtiva no } \\
\text { Brasil (\%) }\end{array}$} & Maixa (Até 21) & 17,5 & 0 & 0 & 17,5 \\
\cline { 2 - 5 } & Média (Acima de 21 e abaixo de 53) & 15 & 27,5 & 7,5 & 50 \\
\hline \multicolumn{2}{|c|}{ Alta (Acima de 53) } & 5 & 15 & 12,5 & 32,5 \\
\hline
\end{tabular}

Legenda: *Pearson qui-square $=7,345 ; \alpha=0,082$ (significante a $10 \%$ ).

Tabela 3 - Número de subsidiárias estrangeiras das MNB segundo a experiência produtiva no exterior*.

\begin{tabular}{|c|c|c|c|c|c|}
\hline & & \multicolumn{3}{|c|}{ NÚMERO DE SUBSIDIÁRIAS ESTRANGEIRAS (\%) } & \multirow{2}{*}{ Total (\%) } \\
\hline & Baixa (Até 5) & Apenas 1 & De 2 a 5 & Acima de 10 & \\
\hline \multirow{2}{*}{$\begin{array}{c}\text { Experiência produtiva no } \\
\text { Exterior (\%) }\end{array}$} & 27,5 & 7,5 & 2,5 & 37,5 \\
\cline { 2 - 5 } & $\begin{array}{c}\text { Média (Acima de 5 e } \\
\text { abaixo de 25) }\end{array}$ & 20 & 12,5 & 10 & 42,5 \\
\cline { 2 - 5 } & Acima de 25 & 2,5 & 5 & 12,5 & 20 \\
\hline \multicolumn{2}{|c|}{ Total (\%) } & 50 & 25 & 25 & 100 \\
\hline
\end{tabular}

Legenda: * Pearson qui-square $=10,345 ; \alpha=0,047$ (significante a $5 \%$. 
Elementos Tecnológicos Determinantes das Capacidades Dinâmicas de Inovação e Cooperação: Um Estudo com as Multinacionais Brasileiras

No que tange à natureza dos parceiros tecnológicos das MNB estudadas, observou-se que os de maior relevância para a inovação foram os clientes nacionais e as ICT públicas nacionais, demonstrando que essas empresas ainda utilizam, basicamente, as fontes tradicionais de inovação que implicam em mecanismos de cooperação muitas vezes já institucionalizados. Já as fontes de inovação que requerem a adaptação ou construção de novos mecanismos cooperativos ainda assumem uma baixa relevância entre as $\mathrm{MNB}$, tais como as redes de inovação internacionais, os start-ups nacionais, os consultores internacionais, as organizações não governamentais nacionais, as associações industriais internacionais, as organizações não governamentais internacionais e os start-ups internacionais. Vale também destacar, conforme aponta Ferro (2010), que a diversidade de parceiros tecnológicos requer de uma empresa um conjunto mais variado de habilidades de cooperação, o que alavanca a sua destreza ao gerenciar as parcerias, neste contexto, as MNB deverão diversificar os seus portfólios de parceiros não apenas para ampliar as fontes de inovação, mas para fortalecer a sua capacidade relacional e ampliar suas competências gerenciais cooperativas (tabela 4).

Tabela 4 - Indicadores do grau de importância da natureza dos parceiros tecnológicos para a inovação.

\begin{tabular}{|c|c|c|c|c|c|c|c|c|c|c|}
\hline \multirow{2}{*}{ CATEGORIAS $*$} & \multicolumn{7}{|c|}{ GRAU DE RELEVÂNCIA (\%) } & \multirow{2}{*}{ NA } & \multirow{2}{*}{ DP } & \multirow{2}{*}{ MD } \\
\hline & 1 & 2 & 3 & 4 & 5 & 6 & 7 & & & \\
\hline Clientes nacionais & 0 & 12,5 & 2,5 & 12,5 & 22,5 & 17,5 & 32,5 & 0 & 1,68 & 5,28 \\
\hline Instituições Científicas e Tecnológicas públicas nacionais & 2,5 & 10 & 5 & 5 & 15 & 27,5 & 30 & 5 & 2,09 & 5,08 \\
\hline Fornecedores nacionais & 7,5 & 5 & 10 & 10 & 20 & 20 & 25 & 2,5 & 2,01 & 4,83 \\
\hline Clientes internacionais & 12,5 & 17,5 & 5 & 7,5 & 15 & 20 & 20 & 2,5 & 2,25 & 4,28 \\
\hline Instituições Científicas e Tecnológicas privadas nacionais & 2,5 & 17,5 & 10 & 7,5 & 20 & 22,5 & 12,5 & 7,5 & 2,13 & 4,20 \\
\hline Instituições Científicas e Tecnológicas públicas internacionais & 12,5 & 10 & 2,5 & 7,5 & 25 & 22,5 & 10 & 10 & 2,31 & 4,00 \\
\hline Fornecedores internacionais & 20 & 5 & 10 & 17,5 & 10 & 27,5 & 7,5 & 2,5 & 2,12 & 3,98 \\
\hline Consultores nacionais & 12,5 & 17,5 & 12,5 & 7,5 & 12,5 & 22,5 & 7,5 & 7,5 & 2,20 & 3,65 \\
\hline Instituições Científicas e Tecnológicas privadas internacionais & 16,8 & 14,3 & 8,4 & 8,4 & 14,5 & 15,7 & 11,3 & 10,5 & 2,14 & 3,63 \\
\hline Órgãos reguladores nacionais & 15 & 12,5 & 10 & 5 & 15 & 20 & 10 & 12,5 & 2,40 & 3,55 \\
\hline Associações industriais nacionais & 30 & 17,5 & 2,5 & 2,5 & 17,5 & 17,5 & 10 & 2,5 & 2,33 & 3,45 \\
\hline Órgãos reguladores nacionais & 15 & 10 & 15 & 5 & 20 & 17,5 & 5 & 12,5 & 2,24 & 3,40 \\
\hline Redes de inovação nacionais & 17,7 & 14,4 & 8,7 & 8,2 & 14,1 & 15,6 & 10,2 & 11,1 & 2,04 & 3,33 \\
\hline Concorrentes nacionais & 20 & 20 & 12,5 & 10 & 10 & 12,5 & 7,5 & 7,5 & 2,14 & 3,15 \\
\hline Concorrentes internacionais & 25,0 & 12,5 & 5 & 15 & 15 & 0 & 15 & 12,5 & 2,35 & 3,05 \\
\hline Redes de inovação internacionais & 18 & 14,3 & 8,9 & 8,2 & 14 & 15,3 & 9,7 & 11,5 & 2,02 & 2,90 \\
\hline Start-ups nacionais & 20 & 20 & 12,5 & 2,5 & 12,5 & 5 & 12,5 & 15 & 2,33 & 2,88 \\
\hline Consultores internacionais & 15 & 27,5 & 12,5 & 10 & 15 & 5 & 0 & 15 & 1,80 & 2,53 \\
\hline Organizações não governamentais nacionais & 25 & 12,5 & 5 & 7,5 & 7,5 & 10 & 7,5 & 25 & 2,39 & 2,45 \\
\hline Associações industriais internacionais & 35,0 & 17,5 & 7,5 & 10 & 5 & 10 & 2,5 & 12,5 & 1,99 & 2,35 \\
\hline Organizações não governamentais internacionais & 27,5 & 7,5 & 5 & 12,5 & 10 & 12,5 & 0 & 25 & 2,18 & 2,33 \\
\hline Start-ups internacionais & 22,5 & 20 & 15 & 5 & 7,5 & 7,5 & 0 & 22,5 & 1,85 & 2,10 \\
\hline
\end{tabular}

Legenda: $\mathrm{NA}=$ não se aplica; $\mathrm{DP}=$ desvio padrão; $\mathrm{MD}=$ média; $*$ Escala utilizada: 1 para importância reduzida e 7 para importância elevada.

No que tange às atribuições frequentemente assumidas pela matriz, subsidiárias e parceiros tecnológicos, contatou-se que as atividades de prospecção tecnológica $(37,5 \%)$ e o compartilhamento de conhecimentos e inovações $(47,5 \%)$ estão predominantemente dispersos entre esses atores. No entanto, verificou-se uma forte centralização na matriz das atividades de desenvolvimento tecnológico (40\%), customização de produtos e processos $(45 \%)$, definição do escopo dos projetos de P\&D desenvolvidos interna $(57,5 \%)$ e cooperativamente $(42,5 \%)$, seleção de novos parceiros tecnológicos $(40 \%)$, gestão do portfólio de projetos de $\mathrm{P} \& \mathrm{D}$ realizados internamente $(62,5 \%)$ e gestão do portfólio de projetos cooperativos $(52,5 \%)$. Já as atividades de engenharia não rotineiras, foram realizadas tanto na matriz como nas subsidiárias estrangeiras em $35 \%$ dos casos analisados, enquanto a pesquisa aplicada foi desenvolvida na matriz (30\%), nos parceiros tecnológicos nacionais $(22,5 \%)$ e dispersa entre a matriz, subsidiárias estrangeiras e parceiros nacionais e internacionais (20\%) (tabela 5). 
Elementos Tecnológicos Determinantes das Capacidades Dinâmicas de Inovação e Cooperação: Um Estudo com as Multinacionais Brasileiras

Tabela 5 - Atribuições frequentemente assumidas pela matriz, subsidiárias e parceiros tecnológicos.

\begin{tabular}{|c|c|c|c|c|c|c|c|c|}
\hline \multirow[b]{2}{*}{ CATEGORIAS } & \multicolumn{8}{|c|}{ LOCAL ONDE A ATIVIDADE É REALIZADA (\%) } \\
\hline & $\begin{array}{c}\text { Apenas } \\
\text { na matriz }\end{array}$ & $\begin{array}{l}\text { Apenas nas } \\
\text { subsidiárias } \\
\text { estrangeiras }\end{array}$ & $\begin{array}{l}\text { Na matriz e } \\
\text { nas } \\
\text { subsidiárias } \\
\text { estrangeiras }\end{array}$ & $\begin{array}{l}\text { Apenas nos } \\
\text { parceiros } \\
\text { tecnológicos } \\
\text { nacionais }\end{array}$ & $\begin{array}{l}\text { Apenas nos } \\
\text { parceiros } \\
\text { tecnológicos } \\
\text { internacionais }\end{array}$ & $\begin{array}{c}\text { Nos parceiros } \\
\text { tecnológicos } \\
\text { nacionais e } \\
\text { internacionais }\end{array}$ & $\begin{array}{c}\text { Na matriz, } \\
\text { nas } \\
\text { subsidiárias } \\
\text { estrangeiras e } \\
\text { nos parceiros } \\
\text { nacionais e/ou } \\
\text { internacionais }\end{array}$ & $\begin{array}{l}\text { Não } \\
\text { se } \\
\text { aplica }\end{array}$ \\
\hline $\begin{array}{l}\text { Prospecção de tendências } \\
\text { tecnológicas e científicas }\end{array}$ & 32,5 & 0 & 12,5 & 2,5 & 2,5 & 10 & 37,5 & 2,5 \\
\hline $\begin{array}{c}\text { Customização de produtos e } \\
\text { processos }\end{array}$ & 45 & 0 & 35 & 0 & 0 & 2,5 & 12,5 & 5 \\
\hline Pesquisa aplicada & 30 & 0 & 10 & 22,5 & 5 & 5 & 20 & 7,5 \\
\hline Engenharia não rotineira & 32,5 & 0 & 35 & 0 & 0 & 2,5 & 12,5 & 17,5 \\
\hline $\begin{array}{c}\text { Compartilhamento de } \\
\text { conhecimentos, inovações e } \\
\text { tecnologias }\end{array}$ & 17,5 & 0 & 12,5 & 0 & 2,5 & 10 & 47,5 & 10 \\
\hline $\begin{array}{c}\text { Desenvolvimento } \\
\text { tecnológico } \\
\end{array}$ & 40 & 0 & 22,5 & 0 & 2,5 & 5 & 25 & 5 \\
\hline $\begin{array}{l}\text { Gestão do portfólio de } \\
\text { projetos cooperativos }\end{array}$ & 52,5 & 0 & 15 & 0 & 0 & 7,5 & 12,5 & 12,5 \\
\hline $\begin{array}{l}\text { Seleção de novos parceiros } \\
\text { científicos e tecnológicos }\end{array}$ & 40 & 0 & 30 & 0 & 0 & 12,5 & 10 & 7,5 \\
\hline $\begin{array}{l}\text { Definição do escopo dos } \\
\text { projetos cooperativos }\end{array}$ & 42,5 & 0 & 17,5 & 0 & 0 & 2,5 & 25 & 12,5 \\
\hline $\begin{array}{c}\text { Gestão do portfólio de } \\
\text { projetos de P\&D realizados } \\
\text { internamente }\end{array}$ & 62,5 & 0 & 12,5 & 0 & 0 & 7,5 & 12,5 & 5 \\
\hline $\begin{array}{c}\text { Definição do escopo dos } \\
\text { projetos de P\&D } \\
\text { desenvolvidos internamente }\end{array}$ & 57,5 & 0 & 17,5 & 0 & 0 & 2,5 & 20 & 2,5 \\
\hline
\end{tabular}

Os resultados das atribuições técnicas e gerencias de P\&D interno e cooperativo evidenciaram que as MNB aproveitam a inserção internacional para identificar, absorver e, posteriormente, disseminar tendências e conhecimentos na sua rede de subsidiárias e parceiros tecnológicos, obtendo vantagens ao aproveitar os reservatórios globais de conhecimento, o que reforça, portanto, as discussões de Porto et al. (2010) e de Bartlett e Ghoshal (1992) sobre a internacionalização como estratégia para sentir e explorar as oportunidades locais. No entanto, nota-se que essas empresas ainda concentram as atividades de P\&D e de gestão da inovação nas matrizes, com o intuito de centralizar a massa crítica e promover sinergias no que tange ao desenvolvimento dos projetos internos e cooperativos de P\&D.

Esses resultados reforçam os achados de Chiesa (2000) e Gassmann e Zedtwitz (1999) que tratam da centralização do P\&D em algumas unidades centrais, geralmente, matriz ou centros de excelência, cujo ponto crítico é a impossibilidade de se desenvolver, efetivamente, atividades internas e cooperativas de P\&D nas subsidiárias estrangeiras o que, consequentemente, inviabiliza a geração de uma capacidade dinâmica de cooperação tecnológica na rede de subsidiárias estrangeiras e de parceiros internacionais, também conhecida como capacidade relacional (Wassmer, 2010).

Outro ponto relevante é que, a autonomia das subsidiárias estrangeiras das MNB ainda está, predominantemente, limitada à realização de engenharia não rotineira e de prospecção tecnológica com o intuito de se adaptar os produtos e processos ao mercado local, o que restringe a iniciativa dessas unidades de efetivamente gerarem inovações locais e/ou globais. Esses resultados convergem para as discussões de Ambos e Schlegelmilch (2007), pois como a autonomia operacional não é algo efetivo para as subsidiárias estrangeiras das MNB fica evidente que essas unidades terão dificuldades para tomar suas 
próprias decisões sobre a cooperação com empresas e organizações externas estrangeiras, o que pode inviabilizar a sua capacidade para explorar e gerenciar as fontes externas de inovação e melhorar a sua base de recursos e o seu desempenho inovador.

\subsection{Análise dos Elementos Tecnológicos Determinantes dos Resultados da Cooperabilidade}

A técnica de regressão multivariada busca verificar a influência de cada variável quando todas elas são tomadas em conjunto (Hair et al., 2005). Destaca-se ainda que os pré-requisitos das regressões geradas foram atendidos, conforme indicam os testes de normalidade (Kolmogorov-Smirnov e Shapiro-Wilk) e os testes de colinearidade (VIF) apresentados nas tabelas 11 e 12. Além disso, deve-se pontuar que os coeficientes de Alpha de Cronbach foram superiores a $80 \%$, atestando que as variáveis compostas do estudo são explicadas pelo conjunto de categorias que as constituem (tabela 6).

Tabela 6 - Coeficiente de Alpha de Cronbach.

\begin{tabular}{|l|c|}
\hline \multicolumn{1}{|c|}{ VARIÁVEIS COMPOSTAS CONSIDERADAS NOS MODELOS DE ANÁLISE } & COEFICIENTE \\
\hline Capacitação Tecnológica* & 0.83 \\
\hline Resultados da Cooperabilidade** & 0.93 \\
\hline
\end{tabular}

Legenda: Variáveis independentes compostas* e dependentes compostas** que utilizam escala likert: 1 para frequência ou importância reduzida e 7 para frequência ou importância elevada.

A seguir é apresentada a análise fatorial das variáveis compostas: Capacitação Tecnológica e Resultados da Cooperabilidade (tabelas 7 e 8 ). Especificamente a tabela 7 deixa evidente que 3 fatores explicam $76 \%$ da variância das respostas sobre a importância das estratégias de capacitação tecnológica adotadas pelas MNB, com significância de $1 \%$. Esses fatores explicativos e suas respectivas categorias constituintes possibilitaram a seguinte classificação: (fator 1) Estratégias de capacitação dos fluxos de saída da inovação aberta; (fator 2) Estratégias de capacitação dos fluxos de entrada da inovação aberta; e (fator 3) Estratégias de capacitação em P\&D interno e cooperativo. Destaca-se ainda que o maior grau de explicação está atrelado ao fator 3 (44\%), ou seja, às estratégias de capacitação em P\&D interno e cooperativo, seguido dos fatores $1(16 \%)$ e $2(16 \%)$ que envolvem, respectivamente, os fluxos de saída e de entrada de conhecimentos e tecnologias previstos pela inovação aberta.

Tabela 7 - Fatores da importância das estratégias de capacitação tecnológica adotadas pelas MNB.

\begin{tabular}{|l|c|c|}
\hline \multicolumn{1}{|c|}{ FATORES* } & $\begin{array}{c}\text { CARGA } \\
\text { FATORIAL }\end{array}$ & $\begin{array}{c}\text { EXPLICADA } \\
\text { ACUMULADA }\end{array}$ \\
\hline Fator 1: Práticas de capacitação dos fluxos de saída da inovação aberta & 0,694 \\
\hline Investimento em empresas com tecnologias promissoras ou com potencial de gerá-las & \multirow{1}{*}{0,643} \\
\hline $\begin{array}{l}\text { Intercâmbio tecnológico de know-how sem licenciamento de tecnologias inéditas } \\
\text { (patentes) onde duas ou mais empresas trocam entre si tecnologias próprias, a fim de } \\
\text { atingir objetivos estratégicos, sem necessariamente haver um acordo de licenciamento do } \\
\text { tipo cross-licencing }\end{array}$ & \\
\hline Licenciamento de patentes e da propriedade intelectual para outras empresas & 0,582 \\
\hline $\begin{array}{l}\text { Criação de uma nova empresa, seja um spin-off própria ou uma joint venture, para } \\
\text { disseminar e compartilhar competências tecnológicas }\end{array}$ & 0,486 \\
\hline Fator 2: Práticas de capacitação dos fluxos de entrada da inovação aberta & \\
\hline Benchmarking tecnológico de concorrentes / fornecedores & 0,786 \\
\hline $\begin{array}{l}\text { Aquisições de empresas para a otimização dos esforços em P\&D e inovação, notadamente } \\
\text { start-ups }\end{array}$ & 0,683 \\
\hline Compra de tecnologias externas (patenteadas ou não) & 0,673 \\
\hline Fusões entre empresas para a otimização dos esforços em P\&D e inovação & 0,635 \\
\hline $\begin{array}{l}\text { Financiamento de centros de pesquisa para ganhar agilidade em P\&D e agregar ideias } \\
\text { externas e esforços às atividades de pesquisa }\end{array}$ & 0,561 \\
\hline Fator 3: Práticas de capacitação em P\&D interno e cooperativo & $\mathbf{3 2 \%}$ \\
\hline $\begin{array}{l}\text { Criação na matriz de uma área ou unidade voltada ao desenvolvimento de P\&D e demais } \\
\text { atividades inovadoras }\end{array}$ & 0,945 \\
\hline
\end{tabular}


Elementos Tecnológicos Determinantes das Capacidades Dinâmicas de Inovação e Cooperação: Um Estudo com as Multinacionais Brasileiras

\begin{tabular}{|l|c|}
\hline Treinamento e capacitação contínua da equipe de P\&D & 0,904 \\
\hline Contratação de consultorias especializadas em P\&D e inovação & 0,874 \\
\hline $\begin{array}{l}\text { Desenvolvimento de um projeto piloto de inovação aberta para definir e, posteriormente, } \\
\text { nivelar procedimentos e rotinas administrativas }\end{array}$ & 0,851 \\
\hline Estabelecimento de parcerias contínuas com ICT nacionais & 0,821 \\
\hline $\begin{array}{l}\text { Criação nas subsidiárias estrangeiras de uma área ou unidade voltada ao desenvolvimento } \\
\text { de P\&D e demais atividades inovadoras }\end{array}$ & 0,728 \\
\hline Estabelecimento de parcerias contínuas com ICT internacionais & 0,635 \\
\hline $\begin{array}{l}\text { Realização de projetos cooperativos com escopo definido, focadas nas atividades de } \\
\text { pesquisa que antecedem as fases de criação e desenvolvimento propriamente dito de novos } \\
\text { produtos e tecnologias }\end{array}$ & 0,626 \\
\hline $\begin{array}{l}\text { Realização de projetos cooperativos de curto prazo focados no desenvolvimento de uma } \\
\text { tecnologia, de um produto ou de uma linha de produtos específicos já existentes. }\end{array}$ & 0,568 \\
\hline $\begin{array}{l}\text { Realização de projetos cooperativos com escopo aberto, podendo configurar uma rede, } \\
\text { com o objetivo de investigar um problema ou desafio tecnológico comum e gerar } \\
\text { resultados que possam servir como base para apoiar futuros pesquisa e desenvolvimentos } \\
\text { tecnológicos }\end{array}$ & 0,501 \\
\hline
\end{tabular}

Legenda: $* \mathrm{KMO}=0,758 ;$ Chi-square $=882,345 ; p=1 \%$.

A partir da tabela fatorial 8 , contatou-se que 2 fatores explicam $85 \%$ da variância das respostas sobre a frequência com que os resultados foram alcançados nos projetos cooperativos das parcerias das MNB, com significância de $1 \%$. A análise dos fatores gerados, bem como das suas respectivas categorias constituintes, resultou na seguinte classificação: (fator 1) Resultados tecnológicos da cooperabilidade e (fator 2) Resultados gerenciais da cooperabilidade. Dessa forma, evidenciou-se que o maior grau de explicação está atrelado ao fator 2 (53\%), ou seja, ao alcance de resultados gerenciais nos projetos cooperativos, seguido do fator 1 (32\%) que trata da obtenção de resultados de cunho tecnológico.

Tabela 8 - Fatores da frequência com que os resultados foram alcançados nos projetos cooperativos.

\begin{tabular}{|c|c|c|}
\hline FATORES* & $\begin{array}{c}\text { CARGA } \\
\text { FATORIAL }\end{array}$ & $\begin{array}{l}\text { VARIÂNCIA } \\
\text { EXPLICADA }\end{array}$ \\
\hline Fator 1: Resultados tecnológicos da cooperabilidade & & $32 \%$ \\
\hline Geração de novos produtos e processos & 0,769 & \\
\hline Surgimento de novas tecnologias & 0,746 & \\
\hline Depósito de pedidos de patentes & 0,662 & \\
\hline Geração de novos métodos de marketing & 0,643 & \\
\hline Pedido de registro de marcas & 0,628 & \\
\hline Depósito de registro de softwares & 0,583 & \\
\hline Licenciamento de tecnologias & 0,503 & \\
\hline Surgimento de novos negócios & 0,453 & \\
\hline Geração de novos métodos organizacionais & 0,447 & \\
\hline Fator 2: Resultados gerenciais da cooperabilidade & & $85 \%$ \\
\hline Estabelecimento de novas parcerias tecnológicas & 0,912 & \\
\hline Cumprimento dos prazos & 0,806 & \\
\hline Cumprimento dos orçamentos & 0,824 & \\
\hline Alcance dos objetivos & 0,752 & \\
\hline
\end{tabular}

Legenda: $* \mathrm{KMO}=0,967 ;$ Chi-square $=957,368 ; p=1 \%$.

Cabe destacar que depois de gerados os fatores das variáveis compostas destacadas na tabela 7 e 8 , estes foram submetidos à análise de correlação para se evitar nas regressões a incidência de problemas de multicolinearidade (variáveis independentes correlacionadas, com $r \geq 80 \%$ ) e eliminar também as variáveis independentes com correlação ínfima perante às variáveis dependentes $(\mathrm{r}<10 \%)$, análises essas que também foram realizadas com as variáveis dummy (tabelas 9 e 10).

Quanto à análise de correlação da tabela 9, verificou-se uma alta correlação entre os seguintes fatores (X2) Práticas de capacitação dos fluxos de entrada da inovação aberta e (X3) Práticas de capacitação em P\&D interno e cooperativo e com o intuito de mitigar a multicolinearidade, foram 
Elementos Tecnológicos Determinantes das Capacidades Dinâmicas de Inovação e Cooperação: Um Estudo com as Multinacionais Brasileiras

eliminados das regressões os fatores altamente correlacionados e com menor correlação perante as dependentes, tais como: o fator $\mathrm{X} 3$ nas regressões dos
(Y1) Resultados Tecnológicos da Cooperabilidade e o fator X2 nas regressões dos (Y2) Resultados Gerenciais da Cooperabilidade.

Tabela 9 - Coeficiente de Correlação de Pearson (r) entre as variáveis independentes compostas (X) contra as variáveis dependentes $(\mathrm{Y})$.

\begin{tabular}{|c|c|c|c|c|}
\hline & & $\mathbf{X 1}$ & $\mathbf{X} 2$ & $\mathbf{X 3}$ \\
\hline $\mathbf{X 1}$ & Práticas de capacitação dos fluxos de saída da inovação aberta & & & \\
\hline $\mathbf{X} 2$ & Práticas de capacitação dos fluxos de entrada da inovação aberta & $12 \%$ & & \\
\hline $\mathbf{X 3}$ & Práticas de capacitação em P\&D interna e cooperativa & $71 \%$ & $88 \%$ & \\
\hline Y1 & RESULTADOS TECNOLÓGICOS DA COOPERABILIDADE & $22 \%$ & $28 \%$ & $11 \%$ \\
\hline Y2 & RESULTADOS GERENCIAIS DA COOPERABILIDADE & $15 \%$ & $10 \%$ & $82 \%$ \\
\hline
\end{tabular}

Já os resultados da tabela 10 indicaram uma alta correlação entre as variáveis dummy (X7) Número de projetos de inovação desenvolvidos com parceiros nacionais e (X8) Número de projetos de inovação desenvolvidos com parceiros internacionais e com o intuito de mitigar a multicolinearidade, foram eliminadas das regressões as variáveis dummy altamente correlacionados e com menor correlação perante as dependentes, tais como: a variável $\mathrm{X} 7$ nas regressões dos (Y1) Resultados Tecnológicos da Cooperabilidade e a variável X8 nas regressões dos (Y2) Resultados Gerenciais da Cooperabilidade.

Tabela 10 - Coeficiente de Correlação de Pearson entre as variáveis dummy $(X)$ e contra as variáveis dependentes (Y).

\begin{tabular}{|c|c|c|c|c|c|c|c|c|c|c|c|}
\hline & & $\mathrm{X} 4$ & X5 & X6 & $\mathrm{X7}$ & $\mathrm{X8}$ & X9 & $\mathbf{X 1 0}$ & X11 & $\mathbf{X 1 2}$ & $\mathbf{X 1 3}$ \\
\hline $\mathbf{X 4}$ & Investimento em P\&D & & & & & & & & & & \\
\hline $\mathbf{X 5}$ & Faturamento dos novos produtos & $21 \%$ & & & & & & & & & \\
\hline X6 & $\begin{array}{l}\text { Número de projetos de inovação desenvolvidos } \\
\text { internamente }\end{array}$ & $-13 \%$ & $-10 \%$ & & & & & & & & \\
\hline $\mathbf{X 7}$ & $\begin{array}{l}\text { Número de projetos de inovação desenvolvidos } \\
\text { com parceiros nacionais }\end{array}$ & $-28 \%$ & $-10 \%$ & $73 \%$ & & & & & & & \\
\hline $\mathrm{X8}$ & $\begin{array}{l}\text { Número de projetos de inovação desenvolvidos } \\
\text { com parceiros internacionais }\end{array}$ & $-28 \%$ & $-10 \%$ & $73 \%$ & $100 \%$ & & & & & & \\
\hline X9 & $\begin{array}{l}\text { Número de projetos de inovação desenvolvidos } \\
\text { com parceiros nacionais e internacionais }\end{array}$ & $3 \%$ & $-10 \%$ & $24 \%$ & $22 \%$ & $22 \%$ & & & & & \\
\hline $\mathbf{X 1 0}$ & Anos de experiência em P\&D na matriz & $-11 \%$ & $28 \%$ & $23 \%$ & $14 \%$ & $14 \%$ & $0 \%$ & & & & \\
\hline $\mathbf{X 1 1}$ & $\begin{array}{l}\text { Anos de experiência em P\&D nas subsidiárias } \\
\text { estrangeiras }\end{array}$ & $-10 \%$ & $17 \%$ & $22 \%$ & $31 \%$ & $31 \%$ & $1 \%$ & $37 \%$ & & & \\
\hline $\mathbf{X 1 2}$ & Anos de experiência em cooperação nacional & $21 \%$ & $25 \%$ & $30 \%$ & $13 \%$ & $13 \%$ & $13 \%$ & $52 \%$ & $16 \%$ & & \\
\hline $\mathbf{X 1 3}$ & Anos de experiência em cooperação internacional & $1 \%$ & $17 \%$ & $22 \%$ & $16 \%$ & $16 \%$ & $31 \%$ & $59 \%$ & $32 \%$ & $50 \%$ & \\
\hline Y1 & $\begin{array}{l}\text { RESULTADOS TECNOLÓGICOS DA } \\
\text { COOPERABILIDADE }\end{array}$ & $\mathbf{5 0 \%}$ & $42 \%$ & $67 \%$ & $21 \%$ & $38 \%$ & $59 \%$ & $40 \%$ & $55 \%$ & $62 \%$ & $43 \%$ \\
\hline Y2 & $\begin{array}{l}\text { RESULTADOS GERENCIAIS DA } \\
\text { COOPERABILIDADE }\end{array}$ & $13 \%$ & $-15 \%$ & $-26 \%$ & $-31 \%$ & $-21 \%$ & $-16 \%$ & $-15 \%$ & $23 \%$ & $-21 \%$ & $12 \%$ \\
\hline
\end{tabular}

Em relação às regressões, foram gerados cinco modelos para cada variável dependente, cujos coeficientes apresentados nas tabelas 11 e 12 indicam o poder de explicação das variáveis independentes e dummy (elementos da trajetória e insumos tecnológicos) sobre as variáveis dependentes do estudo (resultados tecnológicos e gerenciais da cooperabilidade). Dentre as regressões realizadas, as que apresentaram o melhor poder de explicação foram as calculadas após o teste de multicolinearidade (regressão 1), resultando em um R Quadrado Ajustado de $86 \%$ para os resultados tecnológicos da cooperabilidade (tabela 11) e de $75 \%$ para os resultados gerenciais da cooperabilidade (tabela 12). 
Elementos Tecnológicos Determinantes das Capacidades Dinâmicas de Inovação e Cooperação: Um Estudo com as Multinacionais Brasileiras

Tabela 11 - Resultados das regressões considerando com dependente os resultados tecnológicos da cooperabilidade

\begin{tabular}{|c|c|c|c|c|c|c|c|c|c|c|c|}
\hline \multicolumn{12}{|c|}{ Y1 (variável dependente) = RESULTADOS TECNOLÓGICOS DA COOPERABILIDADE } \\
\hline & & \multicolumn{2}{|c|}{$l^{x}$ Regressã̃o } & \multicolumn{2}{|c|}{$2^{x}$ Regressão } & \multicolumn{2}{|c|}{$3^{x}$ Regressão } & \multicolumn{2}{|c|}{$4^{x}$ Regressão } & \multicolumn{2}{|c|}{$5^{n}$ Regressão } \\
\hline $\begin{array}{c}\text { Independentes e } \\
\text { Dumuny }\end{array}$ & $\begin{array}{c}\text { Classificação } \\
\text { operacional das } \\
\text { variáveis e dos fatores }\end{array}$ & \multicolumn{2}{|c|}{$\begin{array}{c}\text { Após o teste de } \\
\text { multicolinearidade }\end{array}$} & \multicolumn{2}{|c|}{ Com stepwise $5 \%$} & \multicolumn{2}{|c|}{ Com stepwise $10 \%$} & \multicolumn{2}{|c|}{$\begin{array}{c}\text { Com stepwise } \\
15 \%\end{array}$} & \multicolumn{2}{|c|}{$\begin{array}{l}\text { Após o componente } \\
\text { principal }\end{array}$} \\
\hline \multirow{2}{*}{\multicolumn{2}{|c|}{ Constante }} & Coeficientes & VIF & Coeficientes & VIF & Coeficientes & VIF & Coeficientes & VIF & Coeficientes & VIF \\
\hline & & 1,761 & - & $0,503^{*}$ & - & $2,234^{\circ}$ & - & $2,367^{\circ}$ & - & $4,675^{\circ}$ & \\
\hline \multirow{2}{*}{$\begin{array}{l}\text { Independentes } \\
\text { da Trajetória } \\
\text { Tecnológica }\end{array}$} & $\begin{array}{c}\mathrm{Xl}=\text { Egtratégias de } \\
\text { capacitação dos fluxos de saida } \\
\text { da inovação aberta }\end{array}$ & 1,361 & 1,471 & - & 1,289 & - & 1,264 & - & 1,456 & - & 1,521 \\
\hline & $\begin{array}{c}\mathrm{X} 2=\text { Estratégias de } \\
\text { capacitação dos fluxos de } \\
\text { entrada da inovação aberta }\end{array}$ & $1,021^{\bullet}$ & 1,032 & - & 1,267 & - & 1,361 & - & 1,321 & - & 1,269 \\
\hline \multirow{5}{*}{$\begin{array}{l}\text { Dummy dos } \\
\text { insumos } \\
\text { Tecnológicos }\end{array}$} & $\mathrm{X} 4=$ Investimento em P\&D & $0,307^{* * 4}$ & 1,201 & - & 1,356 & - & 1,390 & $0,230^{* * * 4}$ & 1,211 & - & 1,445 \\
\hline & $\begin{array}{l}\text { X5 = Faturamento dos novos } \\
\text { produtos }\end{array}$ & 0,201 & 1,378 & - & 1,389 & - & 1,467 & - & 1,356 & - & 1,423 \\
\hline & $\begin{array}{c}\text { X6 = Número de Projetos de } \\
\text { inovação desenvolvidos } \\
\text { internamente }\end{array}$ & $0,457^{* * *}$ & 1,211 & - & 1,349 & - & 1,378 & $0,534^{* * * *}$ & 1,208 & - & 1,352 \\
\hline & $\begin{array}{l}\mathrm{X} 8 \text { = Número de projetos de } \\
\text { inovação desenvolvidos com } \\
\text { parceiros internacionais }\end{array}$ & 0,894 & 1,456 & - & 1,331 & - & 1365 & - & 1,306 & - & 1,470 \\
\hline & $\begin{array}{c}\mathrm{X} 9=\text { Número de Projetos de } \\
\text { inovação desenvolvidos com } \\
\text { parceiros nacionais e } \\
\text { internacionais }\end{array}$ & $0,286^{* * *}$ & 1,236 & - & 1,376 & - & 1,402 & $0,346^{* * 4}$ & 1,121 & - & 1,387 \\
\hline \multirow{4}{*}{$\begin{array}{c}\text { Dummy da } \\
\text { Trajetória } \\
\text { Tecnológica }\end{array}$} & $\begin{array}{c}\text { X10 = Experiência em P\&D na } \\
\text { matriz }\end{array}$ & $1,741^{* *}$ & 1,141 & - & 1,312 & - & 1,356 & $1,504 * *$ & 1,124 & - & 1,389 \\
\hline & $\begin{array}{l}\mathrm{X} 11=\text { Experiência em } \mathrm{P} \& \mathrm{D} \\
\text { nas subsidiárias estrangeiras }\end{array}$ & 0,708 & 1,329 & - & 1,287 & - & 1,352 & - & 1,403 & - & 1,254 \\
\hline & $\begin{array}{l}\mathrm{X} 12=\text { Experiência em } \\
\text { cooperação nacional }\end{array}$ & $0,983^{* *}$ & 1,202 & - & 1,320 & - & 1,301 & $0,857^{* *}$ & 1,187 & - & 1,356 \\
\hline & $\begin{array}{c}\text { X13 }=\text { Experiência em } \\
\text { cooperação internacional }\end{array}$ & 0,512 & 1,431 & - & 1,483 & - & 1,462 & - & 1,553 & - & 1,482 \\
\hline \multicolumn{2}{|c|}{ Componente principal } & - & - & - & - & - & - & - & & $0,641^{\circ}$ & \\
\hline \multirow{2}{*}{\multicolumn{2}{|c|}{$\begin{array}{l}\text { RQuadrado Ajustado } \\
\text { Kolmogorov-Smirnov }\end{array}$}} & 0,867 & & 0,619 & & 0,731 & & 0,749 & & 0,587 & \\
\hline & & $0,156^{\circ}$ & & $0,136^{4 *}$ & & $0,141^{\circ}$ & & $0,147^{*}$ & & $0,131^{* *}$ & \\
\hline \multicolumn{2}{|c|}{$\frac{\text { Aomogorov-smurnov }}{\text { Shapiro-Wilk }}$} & $0,982^{*}$ & & $0,957^{* *}$ & & $0,971^{*}$ & & $0,966^{\circ}$ & & $0,942^{* *}$ & \\
\hline
\end{tabular}

Legenda: *p 1\%; $* *$ * 5\%; $* * * p 10 \%$. 
Elementos Tecnológicos Determinantes das Capacidades Dinâmicas de Inovação e Cooperação: Um Estudo com as Multinacionais Brasileiras

Tabela 12 - Resultados das regressões considerando com dependente os resultados gerenciais da cooperabilidade.

\begin{tabular}{|c|c|c|c|c|c|c|c|c|c|c|c|}
\hline \multicolumn{12}{|c|}{ Y2 (variável dependente) = RESULTADOS GERENCIAIS DA COOPERABILIDADE } \\
\hline & & \multicolumn{2}{|c|}{$1^{x}$ Regressão } & \multicolumn{2}{|c|}{$2^{x}$ Regressão } & \multicolumn{2}{|c|}{$3^{x}$ Regressão } & \multicolumn{2}{|c|}{$4^{x}$ Regressão } & \multicolumn{2}{|c|}{5 Regressão } \\
\hline $\begin{array}{l}\text { Independentes } \\
\text { e Dumny }\end{array}$ & $\begin{array}{c}\text { Classificação operacional } \\
\text { das variáveis e dos } \\
\text { fatores }\end{array}$ & \multicolumn{2}{|c|}{$\begin{array}{l}\text { Após o teate de } \\
\text { multicolinearidade }\end{array}$} & \multicolumn{2}{|c|}{ Com stepwise $5 \%$} & \multicolumn{2}{|c|}{ Com stepwise $10 \%$} & \multicolumn{2}{|c|}{ Com stepwise $15 \%$} & \multicolumn{2}{|c|}{$\begin{array}{c}\text { Após o componente } \\
\text { principal }\end{array}$} \\
\hline & & Coeficientes & VIF & Coeficientes & VIF & Coeficientes & VIF & Coeficientes & VIF & Coeficientes & VIF \\
\hline & Constante & 1,121 & - & $0,403^{*}$ & & $2,964^{*}$ & - & $2,957^{*}$ & - & $4,275^{*}$ & - \\
\hline \multirow{2}{*}{$\begin{array}{l}\text { Independentes } \\
\text { da Trajetória } \\
\text { Tecnológica }\end{array}$} & $\begin{array}{c}\text { Xl = Estratégias de } \\
\text { capacitação dos fluxos } \\
\text { de saida da inovação } \\
\text { aberta }\end{array}$ & 0,834 & 1,456 & - & - & - & 1,420 & - & 1,387 & - & 1,511 \\
\hline & $\begin{array}{l}\text { X3 = Estratégias de } \\
\text { capacitação em P\&D } \\
\text { interno e cooperativo }\end{array}$ & $0,907^{*}$ & 1,097 & t & 1,302 & - & 1,361 & - & 1,387 & - & 1,402 \\
\hline \multirow{5}{*}{$\begin{array}{l}\text { Dunnyy dos } \\
\text { Insumos } \\
\text { Tecnológicos }\end{array}$} & $\begin{array}{c}\mathrm{X} 4 \text { = Investimento em } \\
\mathrm{P} \& \mathrm{D}\end{array}$ & 0,578 & 1,364 & - & 1,386 & - & 1,362 & - & 1,423 & - & 1,381 \\
\hline & $\begin{array}{c}\mathrm{X} 5 \text { = Faturamento dos } \\
\text { novos produtos }\end{array}$ & $-0,086$ & 1,342 & - & 1,265 & - & 1,282 & - & 1,361 & - & 1,317 \\
\hline & $\begin{array}{c}\text { X6 = Número de } \\
\text { Projetos de inovação } \\
\text { desenvolvidos } \\
\text { intermamente }\end{array}$ & $-0,734^{8 * 8}$ & 1,211 & - & 1,341 & - & 1,402 & - & 1,417 & - & 1,423 \\
\hline & $\begin{array}{c}\mathrm{X} 7=\text { Número de } \\
\text { projetos de inovação } \\
\text { desenvolvidos com } \\
\text { parceiros nacionais }\end{array}$ & $-0,681$ & 1,461 & - & 1,487 & - & 1,565 & - & 1,323 & - & 1,483 \\
\hline & $\begin{array}{l}\text { X9 = Número de } \\
\text { Projetos de inovação } \\
\text { desenvolvidos com } \\
\text { parceiros nacionais e } \\
\text { intermacionais }\end{array}$ & $-0,312^{* * 8}$ & 1,212 & - & 1,346 & - & 1,372 & - & 1,328 & - & 1,387 \\
\hline \multirow{4}{*}{$\begin{array}{l}\text { Dumeny da } \\
\text { Trajetória } \\
\text { Tecnológica }\end{array}$} & $\begin{array}{c}\mathrm{X} 10=\text { Experiência em } \\
\text { P\&D na matriz }\end{array}$ & $-1,305$ & 1,314 & - & 1,364 & - & 1,342 & - & 1,303 & - & 1,448 \\
\hline & $\begin{array}{c}\text { X11 = Experiência em } \\
\text { P\&D nas subsidiárias } \\
\text { estrangeiras }\end{array}$ & $0,948^{* *}$ & 1,148 & - & 1,362 & $1,033^{8 *}$ & 1,163 & - & 1,342 & - & 1,378 \\
\hline & $\begin{array}{c}\text { X12 = Experiência em } \\
\text { cooperação nacional }\end{array}$ & $-1,845$ & 1,353 & - & 1,431 & - & 1,365 & - & 1,404 & - & 1,370 \\
\hline & $\begin{array}{c}\mathrm{X} 13=\text { Experiência em } \\
\text { cooperação intermacional }\end{array}$ & $1,042^{8 *}$ & 1,206 & - & 1,325 & $1,078^{* *}$ & 1,172 & & 1,328 & - & 1,314 \\
\hline \multicolumn{2}{|c|}{ Componente principal } & - & - & - & - & - & - & - & - & $0,623^{*}$ & - \\
\hline \multicolumn{2}{|c|}{ R Quadrado Ajustado } & 0,756 & & 0,586 & & 0,503 & & 0,478 & & 0,390 & \\
\hline \multicolumn{2}{|c|}{ Kolmogorov-Smirnov } & $0,158^{*}$ & & $0,132 * 8$ & & $0,146^{*}$ & & $0,142^{*}$ & & $0,128^{* *}$ & \\
\hline \multicolumn{2}{|c|}{ Shapiro-Wilk } & $0,985^{*}$ & & $0,945^{8 *}$ & & $0,973^{*}$ & & $0,971^{*}$ & & $0,954^{* *}$ & \\
\hline
\end{tabular}

Legenda: *p 1\%; **p 5\%; ***p $10 \%$. 
Especificamente sobre os elementos determinantes dos resultados da cooperabilidade, constatou-se com base nas regressões geradas que as estratégias de capacitação dos fluxos de entrada da inovação aberta são relevantes para os resultados tecnológicos, com significância de $1 \%$ na primeira regressão (tabela 11). Já para os resultados gerenciais são as estratégias de capacitação em P\&D interno e cooperativo que assumem maior importância, com significância de $1 \%$ também na primeira regressão (tabela 12). A partir desses resultados, pode-se inferir que as estratégias de capacitação tecnológica adotadas pelas MNB para potencializar os fluxos de entrada da inovação aberta e para alavancar o P\&D interno e cooperativo determinam, respectivamente, os resultados tecnológicos e gerenciais da cooperabilidade, rejeitando-se $\mathrm{H}_{05}$, portanto, o grau de relevância das estratégias de capacitação tecnológica determina os resultados da cooperabilidade no modelo analisado.

Sobre as variáveis dummy dos insumos tecnológicos, constatou-se que a porcentagem do faturamento bruto investido em $\mathrm{P} \& \mathrm{D}$, o número de projetos de inovação desenvolvidos internamente e o número de projetos de inovação desenvolvidos com parceiros nacionais e internacionais são relevantes aos resultados tecnológicos da Cooperabilidade, sendo que as três variáveis foram significativas a $10 \%$ na primeira e na quarta regressão (tabela 11). A partir desses resultados é possível inferir que quanto maior o investimento em $\mathrm{P} \& \mathrm{D}$ e maior o portfólio de projetos de inovação internos e de cooperação nacional e internacional, maior serão os resultados tecnológicos obtidos na cooperabilidade, rejeitando-se as hipóteses $\mathrm{H}_{06}, \mathrm{H}_{08}$ e $\mathrm{H}_{011}$, portanto, conclui-se que: o grau de investimento em $P \& D$ determinam os resultados da cooperabilidade; o número de projetos de inovação desenvolvidos internamente determinam os resultados da cooperabilidade; e o número de projetos de inovação desenvolvidos com parceiros nacionais $e$ internacionais determinam os resultados da cooperabilidade.

Para os resultados gerenciais as variáveis dummy dos insumos tecnológicos de maior relevância foram o número de projetos de inovação desenvolvidos internamente e o número de projetos de inovação desenvolvidos com parceiros nacionais e internacionais, ambas com significância de $10 \%$ na primeira regressão (tabela 12), o que possibilitou a rejeição da hipótese $\mathrm{H}_{08}$, evidenciando que o número de projetos de inovação desenvolvidos internamente determinam os resultados da cooperabilidade no modelo analisado, além disso, rejeitou-se $\mathrm{H}_{011}$, portanto, o número de projetos de inovação desenvolvidos com parceiros nacionais $e$ internacionais determinam os resultados da cooperabilidade no modelo em questão. No entanto, foi constatada uma correlação negativa, evidenciando que o tamanho do portfólio de projetos internos e o tamanho do portfólio de projetos de cooperação nacional e internacional determinam negativamente os resultados gerenciais da cooperabilidade, ou seja, quanto maior forem os referidos portfólios, menor será a frequência de resultados que traduzem a eficiência gerencial do processo cooperativo.

Quanto às variáveis dummy da trajetória da cooperabilidade, constatou-se que a experiência em $P \& D$ na matriz e a experiência em cooperação nacional são relevantes aos resultados tecnológicos da Cooperabilidade, com significância de $5 \%$ na primeira e na quarta regressão (tabela 11), sendo possível rejeitar a hipótese $\mathrm{H}_{01}$, indicando que os anos de experiência acumulada em $P \& D$ na Matriz determinam os resultados da cooperabilidade no modelo analisado, além disso, rejeitou-se $\mathrm{H}_{03}$, portanto, conclui-se que os anos de experiência acumulada em cooperação nacional determinam os resultados da cooperabilidade no modelo em questão. Para os resultados gerenciais a experiência em $P \& D$ nas subsidiárias estrangeiras e a experiência em cooperação internacional assumiram maior relevância, com significância de $5 \%$ na primeira e na terceira regressão (tabela 12), sendo possível rejeitar a hipótese $\mathrm{H}_{02}$, evidenciando que os anos de experiência acumulada em P\&D nas subsidiárias estrangeiras determinam os resultados da cooperabilidade no modelo analisado, além disso, $\mathrm{H}_{04}$ também foi rejeitada, portanto, constatou-se que os anos de experiência acumulada em cooperação internacional determinam os resultados da cooperabilidade no modelo em questão.

Vale frisar que quanto maior a experiência acumulada em P\&D nas subsidiárias estrangeiras e em cooperação internacional, mais frequentes serão os resultados gerenciais da cooperabilidade, reforçando a relevância da "função da aprendizagem" na construção da capacidade relacional (Singh, 2007; Heimeriks et al., 2007), que pode ser em partes explicada pelo histórico de exposição das MNB à parceiros tecnológicos estrangeiros que demandaram ao longo dos anos a criação ou a adaptação de práticas cooperativas específicas ao contexto internacional e que, por sua vez, geraram um aprendizado às MNB no tange à gestão da cooperação (Lai et al., 2010; Petruzzelli, 2011).

Por fim, cabe destacar que as demais variáveis não apresentaram significância, portanto, não determinam os resultados tecnológicos e gerenciais da Cooperabilidade. Vale frisar que na quinta regressão calculou-se o componente principal a partir da variabilidade de todas as variáveis originais, 
posteriormente, foi verificado o seu impacto sobre os resultados tecnológicos e gerenciais da cooperabilidade, no entanto, os componentes principais gerados, apesar de significantes a 1\%, apresentaram um baixo poder de explicação quando comparado às demais regressões realizadas $(58 \%$ para os resultados tecnológicos na tabela 11 e $39 \%$ para os resultados gerenciais da cooperabilidade na tabela 12).

\section{CONSIDERAÇÕES FINAIS}

A partir dos resultados obtidos, constatou-se que as MNB mais maduras no contexto internacional e com maior número de subsidiárias estrangeiras são também aquelas que mais acumularam experiência produtiva no contexto nacional, indicando a existência de uma sinergia positiva entre a experiência produtiva nacional e internacional.

Sobre as atribuições técnicas e gerencias do P\&D interno e cooperativo, evidenciou-se que as MNB aproveitam a inserção internacional para identificar, absorver e, posteriormente, disseminar tendências e conhecimentos na sua rede de subsidiárias e parceiros tecnológicos, obtendo vantagens ao aproveitar os reservatórios globais de conhecimento. No entanto, nota-se que as MNB ainda centralizam as atividades de P\&D e de gestão da inovação nas matrizes, com o intuito de concentrar a massa crítica e promover sinergias no que tange ao desenvolvimento dos projetos internos e cooperativos de P\&D. Outro ponto relevante é que a autonomia das subsidiárias estrangeiras das MNB ainda está predominantemente limitada à realização de engenharia não rotineira e de prospecção tecnológica com o intuito de se adaptar os produtos e processos ao mercado local, o que restringe a iniciativa dessas unidades de efetivamente gerarem inovações locais e/ou globais, internas ou cooperativas, enfraquecendo, portanto, as suas competências para explorar e gerenciar as fontes externas de inovação e melhorar a sua base de recursos e o seu, consequente, desempenho inovador global.

Quanto ao impacto dos elementos da trajetória sobre os resultados tecnológicos da cooperabilidade vale destacar a experiência acumulada em $P \& D$ na Matriz e para os resultados gerenciais tem-se a experiência acumulada em P\&D nas subsidiárias estrangeiras e em cooperação internacional, evidenciando que quanto maior a experiência em P\&D na matriz mais efetivos serão os resultados tecnológicos e quando maior a experiência acumulada em P\&D nas subsidiárias estrangeiras e em cooperação internacional, mais efetivos serão os resultados gerenciais da cooperabilidade. Além disso, constatouse que quanto maior o grau de relevância das estratégias de capacitação tecnológica, mais efetivos serão os resultados tanto tecnológicos como gerenciais.
Sobre os insumos que determinam os resultados tecnológicos da cooperabilidade, vale destacar o grau de investimento em P\&D, além disso, deve-se enfatizar que o portfólio de projetos de inovação ( $\mathrm{n}^{\circ}$ de projetos internos e cooperativos), apesar de relevante aos resultados tecnológicos da cooperabilidade, exerce um impacto negativo sobre os resultados gerenciais da cooperabilidade, indicando que as práticas de gestão de portfólios e o consequente alinhamento dos projetos de inovação internos e cooperativos podem estar enviesados nas MNB, assim, à medida que o número de projetos aumenta, pode-se elevar a possibilidade de duplicação de esforços e da manutenção de processos de inovação internos e externos não sinérgicos, resultando em um potencial impacto negativo sobre os resultados gerencias da cooperabilidade.

Considerando a análise agregada dos insumos tecnológicos, conclui-se que quando mais expressivos os investimentos em P\&D e maior o número de projetos internos e cooperativos, mais efetivos serão os resultados tecnológicos, no entanto, à medida que o portfólio de projetos é ampliado, crescem as dificuldades de alinhamento e de gestão das MNB, o que pode afetar negativamente os resultados gerenciais da cooperabilidade.

Com relação às limitações da presente pesquisa, destaca-se que as suas conclusões estão diretamente relacionadas às 60 empresas que participaram do levantamento, uma vez que o seu processo de amostragem foi intencional e não aleatório. Dessa forma, as conclusões devem ser analisadas com parcimônia, uma vez que este tipo de amostragem não permite a realização de generalizações acerca das conclusões obtidas no trabalho. Quanto às propostas de estudos futuros, destacam-se a análise em profundidade da cooperabilidade em multinacionais também de economias desenvolvidas e a realização de estudos quantitativos comparando os elementos determinantes dos resultados da cooperabilidade nas multinacionais dos BRICS (Brasil, Rússia, Índia, China e África do Sul).

\section{REFERÊNCIAS}

Almeida, A et al. (2007). Internacionalização de empresas brasileiras: perspectivas e riscos. Rio de Janeiro: Campus.

Ambos, B., \& Schlegelmilch, B. B. (2007). Innovation and control in the multinational firm: a comparison of political. Strategic Management Journal, 28, 473-486.

Andrade, C. A. A. (2010). Inovação e Externalização: Uma Análise de Capabilities na Indústria Farmacêutica. Tese de Doutorado do Departamento 
A Indústria Bancária Brasileira: Um Estudo sobre as Barreiras de Entrada às Instituições Estrangeiras

de Engenharia de Produção, Escola Politécnica, Universidade de São Paulo: SP.

Asakawa, K., Nakamura, H., \& Sawada, N. (2010). Firms' open innovation policies, laboratories' external collaborations, and laboratories' R \& D performance. Management, 40, 109-123.

Bartlett, C., \& Ghoshal, S. (1992). Gerenciando Empresas no Exterior: a Solução Transnacional. Trad. Maria Cláudia Santos Ratto. São Paulo: Makron Books.

Bercovitz, J., \& Feldmann, M. (2006). Entpreprenerial Universities and Technology Transfer: A Conceptual Framework for Understanding Knowledge-Based Economic Development. Journal of Technology Transfer, 31, 175-188.

Berghe, L. V. D., \& Guild, P. D. (2008). The strategic value of new university technology and its impact on exclusivity of licensing transactions: An empirical study. Journal of Technology Transfer, 33, 91-103.

Bruneel, J., Este, P. D., \& Salter, A. (2010). Investigating the factors that diminish the barriers to university - industry collaboration. Research Policy, 39, 858-868.

Carayannis, E. G., \& Campbell, D. F. J. (2009). Mode 3 and Quadruple Helix : toward a 21st century fractual innovation ecosytem. International Journal of Technology Management, 46, 201-234.

Chesbrough, H., Vanhaverbeke, W., \& West, J. Open innovation: researching a new paradigm. Oxford: Oxford University Press, 2008.

Chiaroni, D., Chiesa, V., \& Frattini, F. (2011). The Open Innovation Journey: How firms dynamically implement the emerging innovation management paradigm. Technovation, 31, 34-43.

Chiesa, V. (2000). Global R\&D Project Management and Organization: a taxonomy. Journal of Product Innovation Management, 17, 341-359.

Cronbach, J. L. (1951). Coefficient alpha and the internal structure of tests. Psychometrika, 16, 297334.

Cyrino, A. B., \& Barcellos, E. P. (2006). Estratégias de Internacionalização: evidências e reflexões sobre as empresas brasileiras. In: TANURE, B.; DUARTE, R. G. (Org.). Gestão Internacional. São Paulo: Saraiva.

Doz, Y., Santos, J., \& Williamson, P. (2001). From Global to Metanational. Boston: Harvard Business School Press.
Engeroff, R., \& Balestrin, A. (2008). Inovação fechada versus inovação aberta: um estudo de caso da indústria de cutelaria.In: Simpósio de Gestão da Inovação Tecnológica, XXV, Brasília. Anais do Simpósio de Gestão da Inovação Tecnológica. Brasília: ANPAD.

Ferro, A. F. P. (2010). Gestão da inovação aberta: práticas e competências em P\&D Colaborativa. Tese de Doutorado do Programa de Pós-Graduação em Política Científica e Tecnológica da Universidade Estadual de Campinas: SP.

Gassmann, O., Enkel, E., \& Chesbrough, H. (2010). The future of open innovation. Management, 40, 213-221.

Gassmann, O., \& Zedtwitz, M. V. (1999). New Concepts and Trends in International $R \& D$ Organization. Research Policy, 28, 231-250.

Gil, A. C. (2002). Métodos e técnicas de pesquisa social. 4 ed. São Paulo: Atlas.

Hair, J. F et al. (2005). Análise Multivariada de Dados. 5 ed. São Paulo: Bookman.

Hanel, P., \& Pierre, M. (2006). Industry-University Collaboration by Canadian Manufacturing Firms. Journal of Technology Transfer, 31, 485-499.

Heimeriks, K. H., Duysters, G., \& Vanhaverbeke, W. (2007). Learning mechanisms and differential performance in alliance portfolios. Strategic Organization, 5, 373-408.

Heimeriks, K. H., Duysters, G., \& Vanhaverbeke, W. (2007). Learning mechanisms and differential performance in alliance portfolios. Strategic Organization, 5. 373-408.

Helfat, C. E. et al. (2007). Dynamic Capabilities: Understanding Strategic Change In Organizations. Oxford: Blackwell Publishing.

Hitt, M. A., Ireland, R. D., \& Hoskisson, R. E. (2008). Administração estratégica: competitividade e globalização. São Paulo: Thomson.

Hoang, H. A., \& Rothaermel, F. T. (2010). Leveraging internal and external experience: exploration, exploitation, and R\&D project performance. Strategic Management Journal, 758, 734-758.

Hoang, H., \& Rothaermel, F. (2005). The effect of general and partner-specific alliance experience on joint R\&D project performance. Academy of Management Journal, 48, 332-345. 
Elementos Tecnológicos Determinantes das Capacidades Dinâmicas de Inovação e Cooperação: Um Estudo com as Multinacionais Brasileiras

Kerlinger, F. N. (1980). Metodologia de Pesquisa em Ciências Sociais. São Paulo: EPU.

Kim, C., \& Song, J. (2007). Creating new technology through alliances: an empiricalinvestigation of joint patents. Technovation, 27, 461-470.

Lai, J. H., Chang, S. C., \& Chen, S. S. (2010). Is experience valuable in international strategic alliances? Journal of International Management, 16, 247-261.

Laursena, K., \& Salterb, A. (2004). Searching high and low: what types of firms use universities as a source of innovation?. Research Policy, 33, 12011215 .

Lavie, D.; Rosenkopf, L. (2006). Balancing exploration and exploitation in alliance formation. Academy of Management Journal, 49, 797-818.

Leydesdorff, L., \& Meyer, M. (2006) Triple Helix indicators of knowledge-based innovation systems: Introduction to the special issue. Research Policy, 35, 1441-1449.

Leydesdorff, L., \& Etzkowitz, H. (2001). The Transformation of University-industry-government Relations. Electronic Journal of Sociology.

Leydesdorff, L., \& Meyer, M. (2006). Triple Helix indicators of knowledge-based innovation systems: Introduction to the special issue. Research Policy, 35, 1441-1449.

Lima, M. C. (2008). Monografia: a engenharia da produção acadêmica. 2. ed. São Paulo: Saraiva.

O’Connor, G. C. (2008). Open, Radical Innovation: Toward an Integrated Model in large established firms. In: CHESBROUGH, $H$. et al. Open Innovation: researching a new paradigm. New York: Oxford.
Petruzzelli, M. (2011). The impact of technological relatedness, prior ties, and geographical distance on university - industry collaborations: A jointpatent analysis. Technovation, 31, 309-319.

Porto, et al. (2010). Gestão de P\&D de empresas multinacionais brasileiras. In: FLEURY, A. (Org.). Gestão Empresarial para a Internacionalização das Empresa Brasileiras. São Paulo: Atlas.

Sampson, R. C. (2005). Experience effects and collaborative returns in R\&D alliances. Strategic Management Journal, 26, 1009-1031.

Santos, J. (2006). O desafio Metanacional. In: TANURE, B.; DUARTE, R. G. (Org.). Gestão Internacional. São Paulo: Saraiva.

Simard, C., \& West, J. (2005). Knowledge Networks and the Geographic Locus of Innovation. Oxford University Press.

Teece, D. J. (2007). Explicating dynamic capabilities: the nature and microfoundations of (sustainable) enterprise performance. Strategic Management Journal, 28, 1319-1350.

Veugelers, R., \& Cassiman, B. (2005). R\&D cooperation between firms and universities. Some empirical evidence from Belgian manufacturing. International Journal of Industrial Organization, 23, 355-379.

Wassmer, U. (2010). Alliance Portfolios: A Review and Research Agenda. Journal of Management, 36, 141171.

West, J., \& Gallagher, S. (2006). Patterns of open innovation in open source software. Open Innovation: Researching a New Paradigm, 235, 1141 